\title{
Development and feasibility study of an app (Ladle) for weight loss and behaviour change
}

\author{
Jane Ogden ${ }^{\text {Corresp., } 1}$, Hazel Maxwell ${ }^{2}$, Adrian Wong ${ }^{2}$ \\ ${ }^{1}$ School of Psychology, University of Surrey, Guildford, Surrey, United Kingdom \\ 2 Fittle App Limited (trading as Ladle), London, United Kingdom \\ Corresponding Author: Jane Ogden \\ Email address: J.Ogden@surrey.ac.uk
}

Background: Weight management interventions involving behaviour change often utilise face to face interventions which include evidence based behaviour change strategies yet are costly and time intensive. In contrast, digital interventions cost less and have a wider reach yet tend to lack an evidence base and are less effective. Aims: The present study therefore aimed to develop an evidence based behaviour change low cost app for weight management and to provide a preliminary analysis of its effectiveness. Methods: The Ladle app was developed through evidence review and feedback from health care professionals and patients and consists of a 12 week course focusing on 6 habits and weight loss facilitated through 36 audio psychological lessons and 12 lessons specifically on the 6 habits. Each lesson was between 2-5 minutes (approx. 168 minutes of lessons). It was evaluated in terms of completion rate, weight loss, adoption of the 6 habits and participant feedback. Results: The results showed a completion rate of $44 \%$, that $52 \%$ of Completers showed weight loss of at least $5 \%, 79 \%$ showed weight loss of at least $3 \%$, the median $\%$ weight lost was $-5 \%$ and the median weight loss was $-3.8 \mathrm{~kg}$. Further, by the end of 12 weeks the majority (>80\%) of participants had adopted 4 of the 6 habits for at least 5 days a week and nearly half (45\%) had adopted the remaining 2 habits for at least 4 days out of 7. Feedback comments were mainly positive $(n=80)$ focusing mostly on the content of the lessons. Some comments were neutral $(n=56)$ and involved a statement of commitment or a description of a challenge and a minority were negative $(n=23)$ describing some technical issues which were addressed as the evaluation progressed. Conclusion: The new Ladle app offers an evidenced based alternative to more intensive face to face interventions. On preliminary analysis it would seem to have lower completion rates than some more intensive interventions but comparable effectiveness for weight loss. It can also improve habits and is less time-intensive and costly to deliver. Participant feedback was generally positive. 
1

2 Development and feasibility study of an app (Ladle) for weight loss and behaviour change

3

4

Jane Ogden ${ }^{1}$, Hazel Maxwell ${ }^{2}$ and Adrian Wong ${ }^{2}$

5

$6 \quad{ }^{1}$ School of Psychology, University of Surrey, Guildford, Surrey, UK

$7 \quad{ }^{2}$ Fittle App Limited (trading as Ladle), London, United Kingdom

8

9

10

11

12 Address for correspondence: Jane Ogden, Professor in Health Psychology, University of Surrey,

13 Guildford, Surrey, GU2 7XH. Email: J.Ogden@surrey.ac.uk

14 


\section{Abstract}

16 Background: Weight management interventions involving behaviour change often utilise face to

17 face interventions which include evidence based behaviour change strategies yet are costly and

18 time intensive. In contrast, digital interventions cost less and have a wider reach yet tend to lack

19 an evidence base and are less effective. Aims: The present study therefore aimed to develop an

20 evidence based behaviour change low cost app for weight management and to provide a

21 preliminary analysis of its effectiveness. Methods: The Ladle app was developed through

22 evidence review and feedback from health care professionals and patients and consists of a 12

23 week course focusing on 6 habits and weight loss facilitated through 36 audio psychological

24 lessons and 12 lessons specifically on the 6 habits. Each lesson was between 2-5 minutes

25 (approx. 168 minutes of lessons). It was evaluated in terms of completion rate, weight loss,

26 adoption of the 6 habits and participant feedback. Results: The results showed a completion rate 27 of $44 \%$, that $52 \%$ of Completers showed weight loss of at least $5 \%, 79 \%$ showed weight loss of 28 at least $3 \%$, the median $\%$ weight lost was $-5 \%$ and the median weight loss was $-3.8 \mathrm{~kg}$. Further, 29 by the end of 12 weeks the majority $(>80 \%)$ of participants had adopted 4 of the 6 habits for at 30 least 5 days a week and nearly half (45\%) had adopted the remaining 2 habits for at least 4 days 31 out of 7 . Feedback comments were mainly positive $(n=80)$ focusing mostly on the content of the

32 lessons. Some comments were neutral $(n=56)$ and involved a statement of commitment or a

33 description of a challenge and a minority were negative $(n=23)$ describing some technical issues

34 which were addressed as the evaluation progressed. Conclusion: The new Ladle app offers an 35 evidenced based alternative to more intensive face to face interventions. On preliminary analysis

36 it would seem to have lower completion rates than some more intensive interventions but

37 comparable effectiveness for weight loss. It can also improve habits and is less time-intensive

38 and costly to deliver. Participant feedback was generally positive. 


\section{Introduction}

40 Overweight and obesity have almost tripled worldwide since 1975, and in $201639 \%$ of all adults

41 were overweight, and 13\% were obese (Ng, Fleming \& Robinson, 2013; NCD-RisC, 106; WHO,

42 2015). The highest rates of obesity are found in Tunisia, the USA, Saudi Arabia and Canada,

43 and the lowest are found in China, Mali, Japan, Sweden and Brazil; the UK, Australia and New

44 Zealand are all placed in the middle of the range (WHO, 2015). Overweight and obesity both

45 have psychological and physical health consequences. They are associated with body

46 dissatisfaction, low self esteem, anxiety, low mood and a general lack of confidence (Foresight,

47 2007; Pereira-Miranda et al, 2017). They also increase the risk of cardiovascular disease, heart

48 attacks, diabetes, joint trauma, back pain, many types of cancer, hypertension and strokes, the

49 likelihood of which increases as a person's BMI increases greater than 25 (Foresight, 2007;

50 Pereira-Miranda et al, 2017; Mokdad et al, 2004; Romero-Corral et al, 2006; Ortega et al, 2017).

51 In the UK the prevalence of diabetes increased from $46 \%$ to $56 \%$ between 1996 and 2005, which

52 can be largely explained by the rise in overweight and obesity (PHE, 2015). Obesity is also

53 directly linked with mortality and decreased life expectancy (Mokdad et al, 2004; Romero-Corral

54 et al, 2006; Ortega et al, 2017; Global BMI Mortality Collaboration, 2016).

Excess body weight also has economic consequences. The global economic cost of

56 obesity is approximately $\$ 2.0$ trillion, or 2.8 percent of global GDP, paralleling the global impact

57 of smoking or armed violence, war, and terrorism (McKinsey, 2014). Further, the toll of obesity

58 on health-care systems is between 2 and 7 percent of all health-care spending in developed

59 economies which increases to $20 \%$ if the cost of treating associated diseases is included

60 (McKinsey, 2011). In the UK, it is estimated that the NHS spent $£ 6.1$ billion on overweight and 
61 obesity-related ill-health in 2014 to 2015 which is higher than the combined cost of the police,

62 fire service and the judicial for the same period (PHE, 2017).

63 Obesity and overweight are therefore a health and financial burden. Many people are

64 motivated to lose weight and studies indicate that about $42 \%$ of the general population report

65 trying to lose weight in the past year; that about $23 \%$ report trying to maintain weight loss in the

66 past year; and about 70\% report having ever dieted to lose weight (Santos et al, 2017). Research

67 has therefore evaluated the effectiveness of different weight loss interventions with a focus on

68 face to face and digital approaches.

Face to face weight management programmes can be group interventions or involve one to one support with a health care professional. Both tend to draw upon a wide range of behavioural strategies such as self monitoring, reinforcement, cognitive restructuring, relapse prevention and nutritional information and involve health care expert input. In terms of effectiveness, a review of the evidence by NICE indicated that by one year, those who had received best case evidence based behavioural management from either public sector or private sector weight management behaviour change services such as the NHS, Weight Watchers or Slimming World showed an average weight loss by one year of $2.22 \mathrm{~kg}$ (Hartmann-Boyce et al 2014; Johns et al, 2014). Furthermore, a large scale analysis of weight loss by Slimming World members showed an overall mean change of $3.9 \mathrm{~kg}$ and a $\%$ weight loss of $-4.4 \%$ by 12 weeks with those who completed at least $75 \%$ of weekly sessions showing a mean weight loss of $6.8 \mathrm{~kg}$ and a \% weight loss of $-7.5 \%$ by 12 weeks (Stubbs et al, 2015). Likewise, a trial of either 12

81 weeks or 52 weeks of Weight Watchers sessions compared to a brief intervention showed mean 82 weight losses by 12 months of $-4.75 \mathrm{~kg}$ (12 wks group) and $-6.76 \mathrm{~kg}$ (52 wks group) both of 
83 which were greater than the brief intervention (Ahern et al, 2017). Further a trial evaluating

84 Slimming World versus advice illustrated $40 \%$ attendance rates at Slimming World, with a mean

85 weight loss of $2.43 \mathrm{~kg}$ by one year follow up (Aveyard et al, 2016). Evidence based face to face

86 interventions are therefore moderately effective in producing weight loss, but are costly due to

87 the need for trained professionals to deliver the programme. For example, in the UK, Weight

88 Watchers on referral costs the NHS $£ 45$ a participant (Ahern et al, 2011) which, if offered to the

8942 million overweight people in the UK would cost the NHS approximately $£ 2$ billion. Further

90 an estimate of the incremental cost of Weight Watchers indicated a cost of $£ 159$ per $\mathrm{kg}$ lost for

9152 weeks and $£ 91$ per kg lost for 12 weeks (Ahern et al, 2017).

In contrast, digital interventions can be delivered at a lower cost than face to face programmes which is reflected in a recent proliferation of online resources and apps. For example, a scoping review in 2015 identified 393 weight loss apps from 4 commercial app stores

95 (Rivera et al, 2016). Of these, however, only 3 had been scientifically evaluated and only 1 involved health care expert involvement. In addition, the majority were limited in their evidence base. For example, the scoping review concluded that although self-monitoring was the most commonly used approach (35.3\%), followed by physical activity support (27.5\%) only a quarter used weight assessment (25.4\%) or healthy eating support (23.2\%) and even less used goal-

100 setting (21.4\%), motivational strategies (7.1\%), social support (5.3\%) or personalized feedback

101 (7/393, 1.8\%) (Rivera et al, 2016). In terms of effectiveness, a systematic review and meta -

102 analysis in 2015 identified 12 research studies evaluating apps for weight loss and concluded that

103 the apps were more effective than control groups resulting in a mean of $-1.04 \mathrm{~kg}$ greater weight

104 loss (Flores Mateo et al, 2015). These apps are therefore less effective than evidence based face 
105 to face programmes (Hartmann-Boyce et al, 2014; Johns et al, 2014; Stubbs et al, 2015; Ahern et

106 al, 2017; Aveyard et al, 2016) yet cost less and can be made available to a wider population.

107 One compromise approach is to provide an app together with human coaching to deliver

108 behavioural strategies. This has been established in the US with the Noom app (Kim et al, 2017;

109 Toro-ramos et al, 2017; Chin et al, 2016; Michaelides et al, 2016). Analysis of this approach

110 indicates greater weight loss compared to apps without coaching ( $-5.2 \%$ by one year follow up)

111 but the employment of human coaches increases the cost of the intervention. For example,

112 consumer access to the Noom course costs $\$ 59(\sim £ 46)$ per month (Noom, 2018) which is more

113 expensive than consumer access to a Weight Watchers face to face programme where costs start

114 at $£ 17.95$ per month (Ahern et al, 2011). In a similar vein, Little et al, (2016) evaluated the

115 impact of combining an internet based intervention with nurse support which was provided either

116 face to face or remotely by email and telephone compared to a control group who received

117 dietician advice and a dietician follow up session. The results showed that both internet groups

118 reported greater weight loss than the control group $(-2.64 \mathrm{~kg}$ by 12 months) and that whereas

119 those who received internet plus face to face nurse support reported a mean weight loss of -4.14

$120 \mathrm{~kg}$ by 12 months those who received internet plus remote nurse support reported a mean weight

121 loss of -3.94 .

122

In summary, the obesity epidemic highlights the need for effective interventions that can

123 reach a wide population. Whilst face to face interventions show some effectiveness they are

124 expensive and limited in their reach. In contrast, apps are less effective but cost less and have

125 wider reach unless human coaching is added which drives the cost up. Some of the key 
126 comparison interventions are shown in Table 1 although definitions, timing of interventions and

127 outcomes measures vary between studies so any comparison is tentative.

-Insert Table 1 about here -

129 There is therefore a need for a low cost digital intervention that can be made available to many but is as effective as a face to face programme. The aim of the present study was therefore

131 to develop and evaluate an evidence based app that provides many of the evidence based

132 behaviour change strategies contained within the face to face approaches, involves health care

133 experts in its development but that is also low cost and available for general use by a wider

134 population. This paper describes the development of the new Ladle app and its preliminary 135 evaluation.

136

137

138 The app development team involved a Professor in Health Psychology with 30 years experience

139 working in eating behaviour and weight management (JO), a registered dietician (SG), two

140 psychology researchers who helped with scripting the habits and lessons (CW and DM), a

141 trained voice artist (RMJ) who delivered the habits and lessons for the audio recordings and the

142 two app developers who run the app company, invested in the app and project managed the

143 whole process (HM, AW).

144 The process of developing the app followed lean start-up methodology (Ries, 2011). In

145 line with this, the development team worked with clinicians and prospective end users of the app

146 throughout the development process to ensure the Ladle app was developed to meet their needs.

147 The steps of the app development were as follows:

Peer) reviewing PDF | (2018:11:32642:3:0:NEW 1 Apr 2019) 
148 Step 1: Needs assessment with health care professionals: Interviews were held with academic

149 researchers specialising in obesity $(n=5)$, Tier 2 and Tier 3 Doctors specialising in obesity $(n=3)$,

150 Consultant Clinical Psychologists $(n=2)$, Dieticians $(n=4)$, Clinical and Programme Leads for

151 Digital Psychological Therapy (both NHS provision and private companies) ( $\mathrm{n}=4$ ), and Clinical

152 Commissioners for Diabetes $(n=5)$ to explore whether a digital, evidenced based, behaviour

153 change app for weight management would be valuable. All those interviewed gave positive

154 feedback.

155 Step 2: Needs assessment with overweight and obese patients: A Google advert describing

156 the proposed Ladle app was set up which drove traffic to an online landing page where a form

157 could be filled out to learn more once the app is ready. Results were $2.6 \%$ un-optimised CTR

158 (Click Through Rate) and 6.3\% conversion to EarlyBird product. This outperforms the average

159 CTR on all Google paid Ads of $\sim 2 \%$, and the average conversion rate for Health and Medical

160 products of $3.27 \%$ (Wordstream, 2018) indicating that a digital, evidenced based, behaviour

161 change app for weight management would be desirable to end users.

162 Step 3: Evidence review: The structure and content of the app was developed in line with three

163 bodies of research evidence (see 25 for a review): i) research exploring the predictors of weight

164 loss and weight loss maintenance (Harmann-Boyce et al, 2014; Johns et al, 2014; Dombrowski et

165 al, 2014; Stubbs et al, 2011; Teixeira et al, 2015; Thomas et al, 2014); ii) research assessing

166 differences between those who lose weight and maintain this weight loss and those who do not

167 using the National Weight Control Registry together with other research (Thomas et al, 2014;

168 Wing et al, 2008; Wing \& Phelan, 2005; Ogden, 2000; Elfhag \& Rossner, 2005; Butryn et al,

169 2007; Epiphaniou \& Ogden, 2010); iii) qualitative research exploring the characteristics of

170 successful weight loss maintainers (Ogden \& Hills, 2008; Epiphaniou \& Ogden, 2010; Greaves 
171 et al, 2017). This research highlights the key role of eating breakfast, planning meals, eating

172 meals rather than snacks, avoiding denial and being more active which are reflected in the 6

173 behavioural habits. These habits are also reflected in the NHS Choices structure for weight

174 management (NHS, 2018) although recent research has questioned to beneficial role of breakfast

175 (Sievert et al, 2019). Furthermore, this research illustrates the importance of psychological

176 strategies such as goal setting and planning; self monitoring, managing emotional eating; a cost

177 benefit analysis of eating behaviour; cognitive restructuring; relapse prevention; recognising the

178 meaning of food; peer support; eating mindfully; having a positive body image; positive

179 reframing; reinforcement; recognising a behavioural model of weight gain; developing a new

180 identity; and self compassion which form the basis of the 36 psychological lessons. This

181 evidence review resulted in a draft course curriculum for the app.

182 Step 4: Focus groups to assess usefulness of proposed course content: Focus groups ( $\mathrm{n}=2)$

183 were conducted with overweight and obese individuals $(\mathrm{n}=19)$ and interviews were carried out

184 with spokespeople from obesity charities and obesity interest groups $(n=4)$ to gain feedback on

185 the draft course curriculum. All feedback was positive and minor amendments were made in line

186 with suggestions.

187 Step 5: Producing the habit and psychological lesson content: The app content was written to

188 reflect the evidence review and focus groups. Two psychology researchers were employed to

189 write the scripts for the app and a registered Dietician who specialises in obesity management

190 wrote the recipe cards and created simple rules to avoid the need for calorie counting. This

191 process was overseen by JO, AW and HM. 
192 Step 6: Building the app: Software developers were employed to build the Ladle digital weight

193 management course including all habits and psychological lessons. This process was overseen

194 by AW and HM.

195 Step 7: Ongoing user feedback: Users were asked for their ongoing feedback to inform

196 continuous improvement of the Ladle app. This involved either face to face or virtual meetings

197 as well as written feedback within the app itself $(n=159$ comments; see results for further

198 details). Changes were made to both the structure and content of the app to reflect this feedback.

199

200 The app

201 The Ladle app delivers a 12 week course focusing on weight loss and 6 behavioural habits

202 supported by 12 short (2-5 mins) audio lessons focusing on the 6 habits and 36 short (2-5 mins)

203 audio psychological lessons. In total the app contains approximately 168 minutes of recorded

204 information relating to the habits and psychological lessons. Each week consists of 1 habit and 3

205 psychological lessons and the 6 behavioural habits are introduced across the first 6 weeks and

206 reinforced in the second half of the course.

207 Week 1:

208 Habit: Healthy breakfast

209 Psychological lessons: Using 'reason for wanting to lose weight' as a mantra to help you make

210 the healthy decision; Understanding impact of healthy eating vs exercise; Disliking unhealthy

211 foods (creating aversion).

212 Week 2:

213 Habit: Eating at planned times

214 Psychological lessons: Weight and behaviour (accepting the overweight and obesity is caused 
215 by behaviour); Practicing hunger tolerance; Emotional eating (replacement activities to

216 emotionally soothe).

217 Week 3:

218 Habit: Healthy lunch

219 Psychological lessons: Finding time (commitment to the course and app); Enjoying fruit and

220 vegetables (finding a 'gateway' vegetable); The 20 minute rule (wait 20 mins if not feeling full up

221 after a meal).

222 Week 4:

223 Habit: Healthy dinner

224 Psychological lessons: Feeling comfortable with smaller portions (re-framing feeling after

225 eating e.g. feeling overfull is uncomfortable); Childhood experiences (how feelings of

226 deprivation in childhood can make you want to overcompensate as an adult with getting the most

227 out of every meal); Dealing with slip-ups (avoiding black and white thinking - getting back on

228 track straight away).

229 Week 5:

230 Habit: Healthy snacks and drinks

231 Psychological lessons: Support from family and friends (what to say to family and friends to get

232 them to support you); Dealing with food pushers (how to say no); Arranging your environment

233 (arranging the home and work place to support healthy living).

234 Week 6:

235 Habit: Being active

236 Psychological lessons: Feeling positive about being active (re-framing getting red and out of

237 breath to something to feel proud of); Positive body image (having a positive body image will 
238 help you look after your body as a valuable resource and not damage it with overeating);

239 Celebrating getting to the halfway point.

240 Week 7:

241 Habit: Healthy breakfast

242 Psychological lessons: Meal planning techniques; Shopping skills (avoiding the isles with

243 unhealthy snacks, understanding the supermarket can be a trigger); Overcoming feelings of

244 unfairness (everyone has some unfairness in life, having to monitor food intake is yours and you

245 can do it / the feeling of unfairness of missing out on this chocolate bar is not as much as the

246 unfairness of being unhealthy).

247 Week 8:

248 Habit: Eating at planned times

249 Psychological lessons: What to do when you're not the cook (practical tips for not overeating 250 when someone else is cooking); Distinguishing between food desire and hunger; Dealing with 251 external triggers e.g walking past a cake shop.

252 Week 9:

253 Habit: Healthy lunch

254 Psychological lessons: Recognising unhelpful rules (e.g. I mustn't waste food) and how to 255 overcome them; Rewarding yourself for progress; Visualisation (meditating on the future, 256 healthier, slimming you thanking you for getting you there).

257 Week 10:

258 Habit: Healthy dinner 
259 Psychological lessons: Overcoming excuses (I can treat myself because ...); Your new identity

260 (re-enforcing that you are now a person who has healthy habits, this is who you are); Using

261 smaller plates.

262 Week 11:

263 Habit: Healthy snacks and drinks

264 Psychological lessons: Assertiveness with those that make you feel bad about controlled eating;

265 Reflecting on the benefits of healthy eating as a mantra to help you make the healthy decision;

266 Mindful eating.

267 Week 12:

268 Habit: Being active

269 Psychological lessons: Priming yourself for exercise; Feeling confident during exercise

270 (practical tips on what to wear, having a workout buddy etc.); Celebrating finishing the course.

271

272 For each habit and lesson participants listened to an audio recording and then answered questions

273 to consolidate their learning. Some also required participants to make personal commitments to

274 use the psychological tool. Information relating to food intake (ie breakfast, lunch, dinner,

275 snacks) uses 'fist size' for portion control rather than calorie counting.

276

277 Expert support: There was also space for participants to ask questions and comment on any

278 aspect of the course. Responses from a Ladle trained professional were given within 24 hours.

279

280 Peer support: Participants could receive peer support by replying to each other's comments on

281 the different lessons. 


\section{Evaluating the app}

284 The app was evaluated as follows:

\section{Methods}

\section{Design}

287 The study used a single arm prospective design with data collected at baseline (time 1) and at the 288 end of each of the 12 weeks (t2-13) to assess retention and completion, weight loss and changes 289 in the behavioural habits. In line with recommendations for a feasibility study a control arm was 290 not included at this early stage of evaluation (Bowen et al, 2009). University of Surrey granted

291 ethical approval to carry out the study within its facilities (Ethical application ref:

292 UEC_2017_067_FHMS).

293

\section{Participants}

295 The app was made available to participants via online adverts (Adwords, Facebook) and through

296 posters at the University. Inclusion criteria were: aged 18+ years; BMI > 25; regular access to the 297 internet. Exclusion criteria were; diagnosed with an eating disorder; pregnant; been advised by a 298 doctor to avoid losing weight. Data was collected over a period of 24 weeks. Participants were 299 only allowed to download the app after reading the participant information sheet and giving 300 written consent as part of the sign up process.

302 Measures

303 Measures were taken of the following: 
304 i)Retention and completion: Retention at each stage of the 12 week course was recorded.

305 Participants were defined as starters if they met the following criteria: completed at least 1 week

306 of the course and signed into the course at least twice in the first month; at least 3 days interval

307 between starting course and any weight submission thereafter. Participants were defined as a

308 completer if were defined as a starter and had completed at least $1 / 3$ of the course. These criteria

309 were set at the onset of the study to reflect what was considered a reasonable definition for a new

310 app.

311 ii)Weight loss: Weight loss was recorded by patient self report through the app throughout the

31212 week course. The weight loss goal of $\geq 5 \%$ was set as research indicates an association with

313 clinically significant benefits in terms of diabetes and a reduction in cardiovascular risk factors

314 (Wing et al, 1987; Aucott, 2008; Blackburn, 1995).

315 iii)Behavioural habits: Participants rated 6 behavioural habits from the week that this habit was

316 introduced as a goal. The habits were: Healthy breakfast; Eating at Planned Times; Healthy

317 Lunch; Healthy Dinner; Healthy Snack and Drinks; Being Active. Participants were asked to rate

318 'How many days over the past week have you [carried out the habit]' on a scale ranging from 1

319 day to 7 days. The behavioural habit goal was set at carrying out the habit at least 5 out of 7

320 days.

321 iv)Participant feedback: Participants also gave free text written feedback throughout the

322 course.

323

324 Data analysis

325 The data were analysed to assess retention and completion rates across the 12 week course, 326 weight loss and adoption of the 6 behavioural habits. In addition, participant free text feedback 
327 was classified into types. Data was analysed using Excel and SPSS and descriptive statistics of

328 distribution. No procedure was used to manage missing values. Missing data were not included

329 in the analysis. No inferential statistics were used so a power calculation was not deemed

330 appropriate.

331

332 Results

333 i)Retention and completion

334 Starters: 83 participants were initially deemed to be starters. However, 1 participant voluntarily

335 withdrew from the trial and 7 participants were excluded from the analysis as their weight

336 submissions were unrealistic on unusable (e.g. stating weight loss of $100 \mathrm{~kg}$ in week 1; writing

337 'no scales'). Accordingly the final sample consisted of 75 starters. Of these $n=63(84 \%)$ were

338 women and $\mathrm{n}=12(16 \%)$ were men. The mean age was 47 yrs SD 12 (range 19-72 yrs) and the

339 mean $\mathrm{BMI}$ at baseline was $31(\mathrm{SD}=6$; range 25-51). Data on ethnic group $(\mathrm{n}=45)$ and post code

$340(n=30)$ was also collected. From this sample 40 were White; 3 were Asian, 1 described

341 themselves as African and 1 described themselves as other. Further, $n=8$ were from deprived

342 areas.

343 Completers: Of the 75 starters, $n=33(44 \%)$ completed the course and $n=42(56 \%)$ dropped out

344 before 4 weeks. The completion rate was therefore $44 \%$. Of these completers 29 were women; 4

345 were men; their mean $\mathrm{BMI}$ at the start of the course was 31 ( $\mathrm{SD}=5$; range 25-50). For those

346 completers with available data for ethnic group $(n=18)$, I was Asian and 17 were White and for

347 those with post code data $(n=9) 5$ were from deprived areas. 
348 Overall, the number of people completing each of the 12 weeks was as follows: Wk 1: 100\%;

349 Wk 2: 80\%; Wk 3: 62\%; Wk 4: 44\%; Wk 5: 28\%; Wk 6: 25\%; Wk 7: 22\%; Wk 8: 16\%; Wk 9:

$350 \quad 13 \%$; Wk 10; 12\% Wk 11: 12\%; Wk 12: 9\%

\section{1 ii)Weight loss}

352 The results showed that of the starters $(n=75), 24 \%(n=18)$ and of the completers $(n=33), 52 \%$

353 ( $n=17$ ) showed weight loss $\geq 5 \%$. Using a less stringent criteria of $\geq 3 \%, 44 \%(n=33)$ of the

354 starters and $79 \%(\mathrm{n}=26)$ of the completers met this criteria. Weight lost in terms of $\mathrm{kg}$ and $\%$

355 weight lost for starters $(n=75)$ and completers $(n=33)$ is shown in Table 2.

-insert Table 2 about here -

357 Some participants, however, showed weight gain. Of the starters $(n=75) 4$ gained weight

$358(0.19 \% ; 0.53 \% ; 1.05 \% ; 2.15 \%)$ and of the completers, 1 gained weight $(1.38 \%) .13(17.3 \%)$

359 starters and $1(3 \%)$ finisher showed no weight change.

360 iii)Behavioural habits

361 By the end of the course the results showed that of the completers $(n=33)$ a large majority had

362 adopted 4 of the 6 behavioural habits for at least 5 days out of 7 as follows: Healthy breakfast:

363 91\% $(n=30)$; Eating at Planned Times: 85\% $(n=28)$; Healthy Lunch: $91 \%(n=30)$; Healthy

364 Dinner: $91 \%(n=30)$. Nearly half had adopted the remaining 2 habits for 4 days out of the 7 :

365 Healthy Snack and Drinks: 45\% $(n=15)$; Being Active: 45\% $(n=15)$.

\section{6 iv) Participant free text feedback}

367 The 75 starters submitted a total of 159 comments. These were classified as either positive $368(\mathrm{n}=80)$, neutral $(\mathrm{n}=56)$ or negative $(\mathrm{n}=23)$. 


\section{Positive comments}

370 The positive comments were classified as relating to lesson content $(n=56)$, lesson format $(n=1)$,

371 losing weight $(n=5)$, overall programme $(n=8)$ and expert support $(n=10)$. Positive lesson

372 content comments were spread across all lessons apart from those relating to 'eating at planned

373 times' which was deemed particularly useful. Examples of comments are as follows:

375 Lesson content: 'So happy to have been motivated to look at weight loss differently. I've been

376 dieting for over 30 years. The fist for measuring is so simple and brilliant'; 'I like the idea of

377 giving the foods I wish to resist an unappealing name'.

378 Lesson format: 'I like the audio and then quiz to check I understood and remembered'.

379 Losing weight: 'So happy to have lost nearly half a stone, I definitely feel thinner and I am

380 getting back into some of my old clothes again'; 'Still going well another half pound lost this

381 week, despite having a week off work and out of the normal routine'.

382 Overall programme: 'I'm really enjoying the course so far - early days I know, but it's making

383 sense'; 'The course is working well for me at the moment'.

384 Expert support: 'Thank you Adrian and team, that's clearer'.

385

386 Neutral comments

387 The neutral comments were classified as relating to statements of commitment or circumstances

388 ( $n=22)$; finding something challenging or expressing a setback $(n=19)$, questions about the

389 course $(n=10)$ or general other $(n=5)$. Of the challenges or setbacks most related either to eating

390 at planned times in terms of the difficulty in having regular meals $(n=7)$ and snacking $(n=7)$.

391 Examples of comments are given below: 
392 Commitment / statement of circumstances: 'Well started today with a healthy breakfast... fist

393 size malted wheats and fist size amount of skimmed milk. Plus my cup of tea, no sugar and a

394 teaspoon of skimmed milk'; 'I will use the app at 8 every night, so ready to start a fresh the next

395 day'.

396 Finding something challenging or expressing a setback: 'I Im finding it difficult not to snack

397 when I am fed up'; 'Whoops, I had a setback last night!! - I had an early evening meal -5pm-

398 come 8:30pm I was starving and went off plan!!!!'

399 Questions: 'What about protein for breakfast such as eggs?'

400

401 Negative comments

402 The negative comments were classified as technical issues $(n=10)$; the content of the course

$403(n=10)$ and failure to lose weight $(n=3)$. Of the technical issues most were about navigation and

404 lesson completion $(n=6)$ and of the content of the course most were about exercise being

405 impractical due to injury or disease $(n=5)$. Examples of negative comments are given below:

406 Technical issues: 'I too have had issues with the programme, I have had to repeat from week 3

407 in order to get to where I was, so you will have double submissions from me'; ' Not relating to

408 this lesson, but I have did have the same issue again with being put back to previous lessons';

409 'Hi, I can't see the play button for the audio lesson? I can see the quiz but not anything to play

410 before? Thanks'.

411 Content: 'Due to a chronic back I can’t exercise'; 'I'm registered disabled; have a chronic back

412 pain chronic fatigue so I'd love to be physically active but sadly can't physically do it'; 'Because

413 I have issues with bowels, I cannot eat anything high in fibre, whole grain and struggle with

414 Dairy'. 
415 Failure to lose weight: 'Not found much to change yet. See how it goes'.

416

\section{Discussion}

418 Obesity and overweight have physical and psychological health consequences (Foresight, 2007;

419 Pereira-Mirnada et al, 2017; Mokdad et al, 2004; Romero-Corral et al, 2006; Ortega, 2017).

420 They also have economic implications for the health care system (McKinsey, 2014). Existing

421 behaviour change programmes either use face to face interventions which are moderately

422 effective, but expensive and have poor reach or digital interventions which have wider reach,

423 cost less but have limited if any effectiveness which is only improved with the availability of a

424 human coach (eg. Hartmann-Boyce et al, 2014; Johns et al, 2014; Stubbs et al, 2015; Ahern et al, 425 2017; Aveyard et al, 2016; Rivera et al, 2016; Chin et al, 2016; Little et al, 2016). The present 426 study therefore aimed to develop and evaluate a digital app based weight loss programme which 427 incorporated the evidence based behaviour change strategies used by face to face interventions 428 but was lower cost and available to the wider population.

429 The resulting Ladle app was developed using 7 steps including expert, health care 430 practitioner and service user input and evidence review. It involved a focus on 6 behavioural 431 habits supported by 36 audio psychological lessons and took 12 weeks to complete. The app was 432 evaluated in terms of completion rates, weight loss, behavioural habits and participant feedback. 433 The results from the evaluation showed that 75 people were considered starters and of 434 these $44 \%(n=33)$ were considered completers. This is lower than some of the studies reporting 435 data for the completion rates for the commercial groups such as Weight Watchers and Slimming 436 World and NHS groups who offer face to face group sessions (eg. Ahern, 2011; Laws, 2004; 437 Logue et al, 2014). It is also lower than available apps that offer a human coach (eg. Pagoto et 
438 al, 2018; Allen et al, 2013; Michaelides et al, 2016). It is, however, comparable or higher than a

439 few of these more intensive interventions (Stubbs et al, 2015; Aveyard et al, 2016). No

440 completion rate data is available for apps without a human coach. This suggests that although a

441 digital app with no coach can have wide reach and attract a high number of users fewer people

442 may complete the course than for a more intensive face to face weight management programme.

443 In terms of actual weight loss, the results were much more positive. In particular, $52 \%$

444 showed at least 5\% weight loss which has been associated with improved health status (Wing et

445 al, 1987; Aucott, 2008) which was comparable or higher than that reported by some face to face

446 interventions (eg. Ahern et al, 2011; Ahern, 2017; Laws, 2004; Logue et al, 2014; Aveyard et al,

447 2016). It is also higher than some digital apps with a coach (Michaelides et al, 2016; Allen et al,

448 2013). In addition, $72 \%$ showed greater than 3\% weight loss which also brings benefits, not only

449 in terms of health but also as an incentive to persist with weight loss efforts. Furthermore, in

450 terms of absolute weight loss (mean $-3.8 \mathrm{~kg}$; median $-3.5 \mathrm{~kg}$ ) or percentage weight loss (mean

$4514.65 \%$; median -5\%) Ladle was comparable to available data for several face to face

452 interventions (eg. Aveyard et al, 2016; Logue et al, 2014; Ahern et al, 2011) and an improvement

453 on apps with no human coach (eg. Turner McGrievy et al, 2011; Laing et al, 2013).

454 The Ladle app was also evaluated in terms of 6 behavioural habits, namely healthy

455 breakfast, lunch, dinner, healthy snacks and drinks, eating at planned times and being active

456 which have been consistently linked with weight loss (Ogden, 2018; NHS, 2018). The results

457 showed that by the end of the 12 week course the large majority of participants had adopted 4 of

458 the 6 habits and nearly half had adopted the remaining two habits which should not only bring

459 about immediate health benefits but set the scene for longer term behaviour change and weight

460 loss in the future. 
Finally the app was evaluated in terms of participant feedback which was mostly positive.

462 In particular, participants were extremely positive about the content of the lessons. Their neutral

463 comments described statements of commitment and any challenges they faced with adhering to

464 the programme and the negative comments mostly reflected technical issues which were

465 addressed throughout the evaluation. The app was therefore found to be acceptable to this

466 patient group.

467 There are some problems with the current study that need to be considered. First the

468 study utilised a single arm prospective design without randomisation and without a control

469 group. This was due to the desire to collect preliminary data regarding completion rates and

470 weight loss as a first stage to testing the app. Second, weight loss data was collected from within

471 the app and was therefore self report which may reflect issues of social desirability and error.

472 Further, comparisons with existing studies are problematic due to the vast variation in designs

473 used, interventions, duration of interventions, definitions of completions rates and weight loss

474 and whether the data were collected as part of a larger randomised control trial or a service

475 evaluation. These comparisons should therefore be seen as tentative and a preliminary analysis.

476 This present study, however, provides a detailed insight into the process of developing an

477 evidence based app and some preliminary insights into its usefulness and impact on weight loss

478 and habit change.

479 Conclusion

480 In summary, this feasibility study aimed to develop and evaluate a weight loss app that was low

481 cost with a wide reach but based upon the evidence and utilising the evidence based behaviour

482 change strategies associated with sustained weight loss maintenance. The Ladle app offers a 12

483 week course designed to promote 6 key habits and weight loss facilitated by psychological 
484 lessons. The results of the analysis indicate that although completion rates were lower than

485 many face to face interventions and apps with a human coach, weight loss was comparable to

486 several of these more intensive and costly forms of weight management and better than that that

487 achieved by other apps with no human coach. This new app therefore offers an evidence based

488 digital approach to weight management which is as effective as other approaches but can be

489 delivered at lower cost to a wider population.

490

491

492 Acknowledgements

493 The authors are grateful to the help and support of Saran Garcha (Registered Dietitian), Chloe 494 Wood and Daniel Morris (psychology researchers) and Rhiannon Morgan-Jones (trained voice 495 artist).

496 


\section{References}

498 Ahern AL, Wheeler GM, Aveyard P, Boyland EJ, Halford JCG, Mander AP, Woolston J,

499 Thomson AM, Tsiountsioura M, Cole D, Mead BR, Irvine L, Turner D, Suhrcke M, Pimpin L,

500 Retat L, Jaccard A, Webber L, Cohn SR, Jebb SA. Extended and standard duration weight-loss

501 programme referrals for adults in primary care (WRAP): a randomised controlled trial. Lancet.

502 2017 Jun 3;389(10085):2214-2225. doi: 10.1016/S0140-6736(17)30647-5.

503

504 Ahern, A.L., Olson, A.D., Aston, L.M., \& Jebb, S.A. Weight Watchers on prescription: An

505 observational study of weight change among adults referred to Weight Watchers by the NHS.

506 BMC Public Health, 2011June 6, 11, 434.

508 Allen JK, Stephens J, Dennison Himmelfarb CR, Stewart KJ, Hauck S. Randomized controlled 509 pilot study testing use of smartphone technology for obesity treatment. J Obes.

$510 \quad 2013 ; 2013: 151597$.

511

512 Aucott, L.S. Influences of weight loss on long-term diabetes outcomes. Proceedings of Nutrition

513 Society, 2008; February, 67(1), 54-59.

514

515 Aveyard P, Lewis A, Tearne S, Hood K, Christian-Brown A, Adab P, Begh R, Jolly K, Daley A,

516 Farley A, Lycett D, Nickless A, Yu LM, Retat L, Webber L, Pimpin L, Jebb SA. Screening and

517 brief intervention for obesity in primary care: a parallel, two-arm, randomised trial. Lancet. 2016

518 Nov 19;388(10059):2492-2500. doi: 10.1016/S0140-6736(16)31893-1.

519 
520 Blackburn, G. Effect of degree of weight loss on health benefits. Obesity Reviews, 1995;

521 September, 3(Supplement 2), 211s-216s.

522

523

524

525

526

527

528

529

530

531

532

533

534

535

536

537

538

539

540

54

542 543
Bowen DJ, Kreuter M, Spring B, Cofta-Woerpel L, Linnan L, Weiner D, Bakken S,

Kaplan CP, Squiers L, Fabrizio C, Fernandez M. How we design feasibility studies.

Am J Prev Med. 2009 May;36(5):452-7. doi: 10.1016/j.amepre.2009.02.002.

Butryn, M.L., Phelan, S., Hill, J.O., \& Wing, R.R. Consistent self-monitoring of weight: A key component of successful weight loss maintenance. Obesity (Silver Spring), 2007; December, 15(12), 3091-3096.

Chin SO, Keum C, Woo J, Park J, Choi HJ, Woo JT, \& Rhee SY. Successful weight reduction and maintenance by using a smartphone application in those with overweight and obesity. Sci Rep. 2016 Nov 7;6:34563. doi: 10.1038/srep34563.

Dombrowski, S. U., Knittle, K., Avenell, A., Araújo-Soares, V., \& Sniehotta, F. F. Long term maintenance of weight loss with non-surgical interventions in obese adults: systematic review and meta-analyses of randomised controlled trials, British Medical Journal, 2014; Vol. 348, p2646.

Elfhag, K., \& Rössner, S. Who succeeds in maintaining weight loss? A conceptual review of factors associated with weight loss maintenance and weight regain. Obesity Reviews, 2005; February, 6(1), 67-85. 
544 Epiphaniou, E., \& Ogden, J. Evaluating the role of triggers and sustaining conditions in weight

545 loss maintenance. Journal of Obesity, 2010; 1-7; 8594143 Open Access.

546

547 Epiphaniou, E., \& Ogden, J. Successful weight loss maintenance: From a restricted to liberated 548 self. International Journal of Health Psychology, 2010; 15, 887-896.

Flores Mateo G, Granado-Font E, Ferré-Grau C, \& Montaña-Carreras X. Mobile Phone Apps to 552 Promote Weight Loss and Increase Physical Activity: A Systematic Review and Meta-Analysis.

553 Bamidis P, ed. Journal of Medical Internet Research. 2015;17(11):e253. doi:10.2196/jmir.4836.

554 Foresight. Tackling obesities: future choices - project report. The Stationery Office, London;

5552007 http://www.foresight.gov.uk/Obesity/obesity final/Index.html.

556 Global BMI Mortality Collaboration. Body-mass index and all-cause mortality: individual-

557 participant-data meta-analysis of 239 prospective studies in four continents. Lancet. 2016; $558 \quad 388(10046): 776-86$.

559

560 Greaves, C., Poltawski, L., Garside, R., \& Briscoe, S. Understanding the challenge of weight loss

561 maintenance: A systematic review and synthesis of qualitative research on weight loss

562 maintenance. Health Psychology Review, 2017; April 7, 1-19.

563

564 
565 Hartmann-Boyce, J., Johns, D.J., Jebb, S.A., \& Aveyard, P. Behavioural weight management

566 review group: Effect of behavioural techniques and delivery mode on effectiveness of weight

567 management: Systematic review, meta-analysis and meta-regression. Obesity Reviews, 2014;

568 July, 15(7), 598-609.

569

570 Hebden L, Cook A, van der Ploeg HP, King L, Bauman A, Allman-Farinelli M. A mobile health

571 intervention for weight management among young adults: a pilot randomised controlled trial. J

572 Hum Nutr Diet. 2014 Aug;27(4):322-32. doi:10.1111/jhn.12155.

573

574

575 Johns, D.J., Hartmann-Boyce, J., Jebb, S.A., \& Aveyard, P. Behavioural weight

576 management review group: Diet or exercise interventions vs combined behavioural weight

577 management programs: A systematic review and meta-analysis of direct comparisons. Journal of

578 Academy of Nutrition and Dietetics, 2014; October, 114(10), 1557-1568.

579

580 Kim H, Ray CD, \& Veluscek AM. Complementary Support from Facilitators and Peers

581 for Promoting mHealth Engagement and Weight Loss. J Health Commun. 2017

582 Nov;22(11):905-912. doi: 10.1080/10810730.2017.1373876.

583

584 Laing BY, Mangione CM, Tseng CH, Leng M, Vaisberg E, Mahida M, Bholat M,

585 Glazier E, Morisky DE, Bell DS. Effectiveness of a smartphone application for weight loss

586 compared with usual care in overweight primary care patients: a randomized, controlled trial.

587 Ann Intern Med 2014;161 (10 Suppl):S5-12. 
589 Laws R; Counterweight Project Team. A new evidence-based model for weight management in

590 primary care: the Counterweight Programme. J Hum Nutr Diet. 2004 Jun;17(3):191-208.

591

592 Little P, Stuart B, Hobbs FR, Kelly J, Smith ER, Bradbury KJ, Hughes S, Smith PW, Moore

593 MV, Lean ME, Margetts BM, Byrne CD, Griffin S, Davoudianfar M, Hooper J, Yao G, Zhu S,

594 Raftery J, Yardley L. An internet-based intervention with brief nurse support to manage obesity

595 in primary care $(\mathrm{POWeR}+)$ : a pragmatic, parallel-group, randomised controlled trial. Lancet

596 Diabetes Endocrinol. 2016 Oct;4(10):821-8. doi: 10.1016/S2213-8587(16)30099-7.

597

598 Logue J, Allardice G, Gillies M, \& Forde L. Outcomes of a specialist weight management

599 programme in the UK National Health Service: prospective study of 1838 patients. BMJ Open

600 2014;4:e003747.doi:10.1136/bmjopen-2013-003747

601

602 Madigan CD, Daley AJ, Lewis AL, Jolly K, Aveyard P. Which weight-loss programmes are as 603 effective as Weight Watchers(R)?: non-inferiority analysis. Br J Gen Pract. 2014;64(620):e12860436.

605

606 Mokdad, A. H., Marks, J. S., Stroup, D. F., \& Gerberding, J. L. Actual causes of death in the 607 United States, 2000; JAMA, 2004; 291, No. 10, pp. 1238-45.

608

609 NCD Risk Factor Collaboration (NCD-RisC) Trends in adult body-mass index in 200 countries

610 from 1975 to 2014: a pooled analysis of 1698 population-based measurement studies with $19 \cdot 2$

611 million participants. Lancet. 2016;387:1377-1396. 
612

613 NHS (2018). Start the NHS weight loss plan. https://www.nhs.uk/live-well/healthy-weight/start-

614 the-nhs-weight-loss-plan/

615

$616 \mathrm{Ng} \mathrm{M}$, Fleming T, \& Robinson M. Global, regional, and national prevalence of overweight and

617 obesity in children and adults during 1980-2013: a systematic analysis for the Global Burden of

618 Disease Study 2013. Lancet. 2014;384:766-781.

619

620 McKinsey. Overcoming obesity: An initial economic analysis

621 https://www.mckinsey.com/ /media/McKinsey/Business\%20Functions/Economic\%20Studies\%

622 20TEMP/Our\%20Insights/How\%20the\%20world\%20could\%20better\%20fight\%20obesity/MGI

623 _Overcoming_obesity_Full_report.ashx 2014.

624

625 Michaelides A, Raby C, Wood M, Farr K, Toro-Ramos T. Weight loss efficacy of a novel

626 mobile Diabetes Prevention Program delivery platform with human coaching. BMJ Open

627 Diabetes Research and Care 2016;4:e000264. doi:10.1136/bmjdrc-2016000264

628

629 Noom https://web.noom.com 2018

630

631 Ogden, J. The Psychology of Dieting. Routledge: London. 2018.

632

633 Ogden, J. The correlates of long term weight loss: A group comparison study of obesity.

634 International Journal of Obesity, 2000; 24, 1018-1025. 
635

636 Ogden, J., \& Hills, L. Understanding sustained changes in behaviour: The role of life events and 637 the process of reinvention. Health: An International Journal, 2008; 12, 419-437.

638

639 Ortega FB, Lavie CJ, Sui X. Health Effects of Overweight and Obesity in 195

640 Countries. N Engl J Med. 2017 Oct 12;377(15):1495. doi: 10.1056/NEJMc1710026.

641

642

Pagoto S, Tulu B, Agu E, Waring ME, Oleski JL, Jake-Schoffman DE Using the Habit App for

643 Weight Loss Problem Solving: Development and Feasibility Study JMIR Mhealth Uhealth

644 2018;6(6):e145

645

646 Pagoto SL, Waring ME, Schneider KL, Oleski JL, Olendzki E, Hayes RB, Appelhans BM,

647 Whited MC, Busch AM, Lemon SC Twitter-Delivered Behavioral Weight-Loss Interventions: A

648 Pilot Series JMIR Res Protoc 2015;4(4):e123 DOI: 10.2196/resprot.4864

649

650 Pereira-Miranda, E., Costa, P.R., Queiroz, V.A., Pereira-Santos, M., \& Santana, M.L.

651 Overweight and obesity associated with higher depression prevalence in adults: A systematic

652 review and meta-analysis. Journal of American College of Nutrition, 2017; April, 10, 1-11.

653

654 Public Health England. Health matters: obesity and the food environment

655 https://www.gov.uk/government/publications/health-matters-obesity-and-the-food-

656 environment/health-matters-obesity-and-the-food-environment--2 2017.

657 
658 Public Health England. Trends in Obesity. [online]:

659 http://www.noo.org.uk/NOO_about_obesity/trends. 2015,

660

661 Ries, E. The lean start up. Crown Publishing Group: New York. 2011.

662

663 Rivera J, McPherson A, Hamilton J, Birken C, Coons M, Iyer S, Agarwal A,

664 Lalloo C, \& Stinson J. Mobile Apps for Weight Management: A Scoping Review. JMIR

665 Mhealth Uhealth. 2016 Jul 26;4(3):e87. doi: 10.2196/mhealth.5115.

666

667 Romero-Corral, A.R., Montori, V.M., Somers, V.K., Korinek, J., Thomas, R.J., Allison, T.G., \&

668 Jimenez, F.L. (2006). Association of body weight with total mortality and with cardiovascular

669 events in coronary heart disease: A systematic review of cohort studies. Lancet, 368, 666-678.

670

671 Santos, I., Sniehotta, F.F., Marques, M.M., Carraça, E.V., \& Teixeira, P.J.

672 Prevalence of personal weight control attempts in adults: A systematic review and meta analysis.

673 Obesity Reviews, 2017; 18(1), 32-50.

674

675 Sievert K, Hussain SM, Page MJ, Wang Y, Hughes HJ, Malek M \& Cicuttini FM.

676 Effect of breakfast on weight and energy intake: systematic review and

677 meta-analysis of randomised controlled trials. BMJ. 2019 Jan 30;364:142. doi:

678 10.1136/bmj.142.

679 
680 Stubbs RJ, Morris L, Pallister C, Horgan G, Lavin JH. Weight outcomes audit in 1.3 million

681 adults during their first 3 months' attendance in a commercial weight management programme.

682 BMC Public Health. 2015 Sep 10;15:882. doi: 10.1186/s12889-015-2225-0.

683

684

Stubbs, J., Whybrow, S., Teixeira, P., Blundell, J., Lawton, C., Westenhoefer, J., \& Raats, M.

685

Problems in identifying predictors and correlates of weight loss and maintenance: Implications

686 for weight control therapies based on behaviour change. Obesity Reviews, September, 2011;

687 12(9), 688-708.

688

689 Teixeira, P.J., Carraça, E.V., Marques, M.M., Rutter, H., Oppert, J.M., De Bourdeaudhuij, I., \&

690 Brug, J. Successful behavior change in obesity interventions in adults: A systematic review of

691 self-regulation mediators. BMC Medicine, 2015; April 16, 13, 84.

692

693 Thomas, J.G., Bond, D.S., Phelan, S., Hill, J.O., \& Wing, R.R. Weight-loss maintenance for 10

694 years in the National Weight Control Registry. American Journal of Preventive Medicine, 2014;

695 January, 46(1), 17-23.

696

697 Toro-Ramos T, Lee DH, Kim Y, Michaelides A, Oh TJ, Kim KM, Jang HC, \& Lim S.

698 Effectiveness of a Smartphone Application for the Management of Metabolic

699 Syndrome Components Focusing on Weight Loss: A Preliminary Study. Metab Syndr

700 Relat Disord. 2017; Nov;15(9):465-473. doi: 10.1089/met.2017.0062.

701 
702 Turner-McGrievy G, Tate D. Tweets, Apps, and Pods: Results of the 6-month Mobile Pounds

703 Off Digitally (Mobile POD) randomized weight-loss intervention among adults. J Med Internet

704 Res. 2011;13(4):e120. Published 2011 Dec 20. doi:10.2196/jmir.1841

705

706 WHO. Obesity and overweight. Fact sheet N³11. World Health Organization; Geneva: 2015.

707

708 Wing, R.R., Papandonatos, G., Fava, J.L., Gorin, A.A., Phelan, S., McCaffery, J., \& Tate, D.F.

709 Maintaining large weight losses: The role of behavioral and psychological factors. Journal of

710 Consulting and Clinical Psychology, 2008; December, 76(6), 1015-1021.

711

712 Wing, R.R., \& Phelan, S. Long-term weight loss maintenance. American Journal of Clinical

713 Nutrition, 2005; July, 82(Supplement 1), 222S-225S. Review. PubMed PMID: 16002825.

714

715 Wing RR, Koeske R, Epstein LH, Nowalk MP, Gooding W, \& Becker D. Long-term

716 effects of modest weight loss in type II diabetic patients. Arch Intern Med. 1987

717 Oct;147(10):1749-53.

718

719 Wordstream https://www.wordstream.com/ retrieved 11/2018. 


\section{Table 1 (on next page)}

Preliminary comparisons of the Ladle app: Completion Rates and Weight Loss 
2 Table 1: Preliminary comparisons of the Ladle app: Completion Rates and Weight Loss

\begin{tabular}{|c|c|c|c|c|c|c|c|c|c|c|}
\hline Type & Provider & $\begin{array}{l}\text { Duration of } \\
\text { intervention }\end{array}$ & $\begin{array}{l}\text { Completion } \\
\text { rate }\end{array}$ & $\begin{array}{l}\text { Definition of } \\
\text { completer }\end{array}$ & $\begin{array}{l}\% \text { completer } \\
\text { lose } \geq \mathbf{3 \%}\end{array}$ & $\begin{array}{l}\% \text { completers } \\
\text { lose } \geq 5 \%\end{array}$ & $\begin{array}{l}\text { Median kg lost } \\
\text { by completer }\end{array}$ & $\begin{array}{l}\text { Mean kg lost } \\
\text { by completer }\end{array}$ & $\begin{array}{l}\text { Median \% } \\
\text { weight loss } \\
\text { completer }\end{array}$ & REF \\
\hline Face 2 face & $\begin{array}{l}\text { Weight } \\
\text { Watchers }\end{array}$ & 12 wks & $54 \%$ & $\begin{array}{l}\text { Attend all } 12 \\
\text { weekly sessions }\end{array}$ & - & $57 \%$ & -5.4 & - & $-5.6 \%$ & $\begin{array}{l}\text { Ahern et al } \\
(2011)\end{array}$ \\
\hline Face 2 face & $\begin{array}{l}\text { Counter } \\
\text { Weight }\end{array}$ & 12 mths & $51 \%$ & Not defined & - & $43 \%$ & - & - & - & Laws (2004) \\
\hline Face 2 face & $\begin{array}{l}\text { Rosemary } \\
\text { Conley }\end{array}$ & 12 wks & $\begin{array}{l}\text { Not inferior to } \\
W W\end{array}$ & Not defined & $\begin{array}{l}\text { Not inferior to } \\
W W\end{array}$ & $\begin{array}{l}\text { Not inferior to } \\
W W\end{array}$ & $\begin{array}{l}\text { Not inferior to } \\
W W\end{array}$ & $\begin{array}{l}\text { Not inferior to } \\
W W\end{array}$ & $\begin{array}{l}\text { Not inferior to } \\
W W\end{array}$ & $\begin{array}{l}\text { Madigan et } \\
\text { al, (2014) }\end{array}$ \\
\hline Face 2 face & $\begin{array}{l}\text { Slimming } \\
\text { World }\end{array}$ & 12 wks & $\begin{array}{l}\text { Not inferior to } \\
W W\end{array}$ & Not defined & $\begin{array}{l}\text { Not inferior to } \\
W W\end{array}$ & $\begin{array}{l}\text { Not inferior to } \\
W W\end{array}$ & $\begin{array}{l}\text { Not inferior to } \\
W W\end{array}$ & $\begin{array}{l}\text { Not inferior to } \\
W W\end{array}$ & $\begin{array}{l}\text { Not inferior to } \\
W W\end{array}$ & $\begin{array}{l}\text { Madigan et } \\
\text { al, (2014) }\end{array}$ \\
\hline Face 2 face & NHS & 12 wks & $\begin{array}{l}\text { Inferior to } \\
\text { commercial } \\
\text { programmes }\end{array}$ & Not defined & $\begin{array}{l}\text { Inferior to } \\
\text { commercial } \\
\text { programmes }\end{array}$ & $\begin{array}{l}\text { Inferior to } \\
\text { commercial } \\
\text { programmes }\end{array}$ & $\begin{array}{l}\text { Inferior to } \\
\text { commercial } \\
\text { programmes }\end{array}$ & $\begin{array}{l}\text { Inferior to } \\
\text { commercial } \\
\text { programmes }\end{array}$ & & $\begin{array}{l}\text { Madigan et } \\
\text { al, (2014) }\end{array}$ \\
\hline Face 2 face & NHS & 12 mths & $72 \%$ & $\begin{array}{l}\text { At least } 1 / 2 \text { of } \\
\text { course }(4 \text { or } \\
\text { more } \\
\text { appointments) }\end{array}$ & - & $29 \%$ & - & -4.02 & - & $\begin{array}{l}\text { Logue et al, } \\
(2014)\end{array}$ \\
\hline Face to face & $\begin{array}{l}\text { Slimming } \\
\text { World }\end{array}$ & 12 wks & $35 \%$ & $\begin{array}{l}75 \% \text { of weekly } \\
\text { sessions }\end{array}$ & - & - & - & -6.8 & $-7.5 \%$ & $\begin{array}{l}\text { Stubbs et al } \\
(2015)\end{array}$ \\
\hline Face to face & $\begin{array}{l}\text { Slimming } \\
\text { World }\end{array}$ & 12 wks & $40 \%$ & Attendance & - & $\begin{array}{l}25 \% \text { (ITT) } \\
\text { (by } 12 \\
\text { months) }\end{array}$ & - & $\begin{array}{l}-2.9(3 \mathrm{mth}) \\
\text { ITT } \\
-2.43(12 \mathrm{mth}) \\
\text { ITT }\end{array}$ & - & $\begin{array}{l}\text { Aveyard et } \\
\text { al, (2016) }\end{array}$ \\
\hline Face to face & $\begin{array}{l}\text { Weight } \\
\text { Watchers }\end{array}$ & $\begin{array}{l}12 \text { wks } \\
52 \text { wks }\end{array}$ & $\begin{array}{l}88.6 \% \\
91.6 \%\end{array}$ & Attendance & - & $\begin{array}{l}42 \% \text { (ITT) } \\
57 \% \text { (ITT) } \\
\text { (12 month) }\end{array}$ & - & $\begin{array}{l}-4.84 \text { (ITT) } \\
-4.62 \text { (ITT) } \\
(3 \mathrm{mth})\end{array}$ & - & $\begin{array}{l}\text { Ahern et al } \\
(2017)\end{array}$ \\
\hline
\end{tabular}




\begin{tabular}{|c|c|c|c|c|c|c|c|c|c|c|}
\hline $\begin{array}{l}\text { Internet with } \\
\text { nurse support } \\
\text { (FtoF OR } \\
\text { remote) }\end{array}$ & NHS & $\begin{array}{l}\text { PeerJ } \\
6 \text { months }\end{array}$ & $75 \%$ & 3 core sessions & - & $\begin{array}{l}\text { Martor.s. } 28 \% \text { pt } \\
\text { (12mnths) } \\
\text { Remote } 32 \% \\
\text { (12 months) }\end{array}$ & $\begin{array}{l}\text { o be revieweo } \\
\text { - }\end{array}$ & $\begin{array}{l}\text { FtoF -4.14 } \\
\text { (12mths) ITT } \\
\text { Remote }-3.94 \\
\text { (12 mths) ITT }\end{array}$ & & $\begin{array}{l}\text { Little et al } \\
\text { (2016) }\end{array}$ \\
\hline $\begin{array}{l}\text { Digital with } \\
\text { coach }\end{array}$ & $\begin{array}{l}\text { The Habit } \\
\text { app with } \\
\text { councillor } \\
\text { lead FB } \\
\text { group }\end{array}$ & 16 wks & $59 \%$ & $\begin{array}{l}\text { Used app at } \\
\text { least once }\end{array}$ & - & - & - & -3.33 & - & $\begin{array}{l}\text { Pagoto et al, } \\
\text { (2018) }\end{array}$ \\
\hline $\begin{array}{l}\text { Digital with } \\
\text { coach }\end{array}$ & \begin{tabular}{|l|} 
Twitter- \\
Behavioral \\
Weight-Loss
\end{tabular} & 12 wks & - & - & - & - & - & -2.4 & - & $\begin{array}{l}\text { Pagoto et al } \\
\text { (2015) }\end{array}$ \\
\hline $\begin{array}{l}\text { Digital with } \\
\text { coach }\end{array}$ & Noom & 16 wks & $84 \%$ & $\begin{array}{l}\text { Read at least } \\
\text { one article per } \\
\text { week during } \\
\text { any } 9 \text { of the } 16 \\
\text { weeks. ( } 8 \% \text { of } \\
\text { the course) }\end{array}$ & - & $64 \%$ & -6 & - & $-7.5 \%$ & $\begin{array}{l}\text { Michaelides } \\
\text { et al (2016) }\end{array}$ \\
\hline $\begin{array}{l}\text { Digital with } \\
\text { coach }\end{array}$ & The Track & $6 \mathrm{mths}$ & $96 \%$ & $\begin{array}{l}\text { Attended } 6 \\
\text { month } \\
\text { assessment }\end{array}$ & - & $43 \%$ & - & -4.4 & - & $\begin{array}{l}\text { Allen et al } \\
\text { (2013) }\end{array}$ \\
\hline $\begin{array}{l}\text { Digital no } \\
\text { coach }\end{array}$ & Ladle & 12 wks & $44 \%$ & $\begin{array}{l}\text { At least } 1 / 3 \text { of } \\
\text { course (or } 20 \\
\text { lessons) }\end{array}$ & $79 \%$ & $52 \%$ & -3.5 & -3.8 & $-5.0 \%$ & Ladle trial \\
\hline $\begin{array}{l}\text { Digital no } \\
\text { coach }\end{array}$ & $\begin{array}{l}\text { MyFitness } \\
\text { Pal }\end{array}$ & $12 \mathrm{wks}$ & - & - & - & $0 \%$ & -0.06 & - & $0.0 \%$ & $\begin{array}{l}\text { Laing et al } \\
\text { (2013) }\end{array}$ \\
\hline $\begin{array}{l}\text { Digital no } \\
\text { coach }\end{array}$ & $\begin{array}{l}\text { Tweets, } \\
\text { Apps, and } \\
\text { Pods }\end{array}$ & $6 \mathrm{mths}$ & $90 \%$ & $\begin{array}{l}\text { Attended } 6 \\
\text { month } \\
\text { assessment }\end{array}$ & - & - & - & -2.8 & $-2.7 \%$ & $\begin{array}{l}\text { Turner- } \\
\text { McGrievy et } \\
\text { al (2011) }\end{array}$ \\
\hline $\begin{array}{l}\text { Digital no } \\
\text { coach }\end{array}$ & \begin{tabular}{|l|} 
A mobile \\
health \\
intervention \\
for weight \\
management \\
among
\end{tabular} & 12 wks & - & - & - & - & - & -1.6 & - & $\begin{array}{l}\text { Hebden et al } \\
(2014)\end{array}$ \\
\hline
\end{tabular}




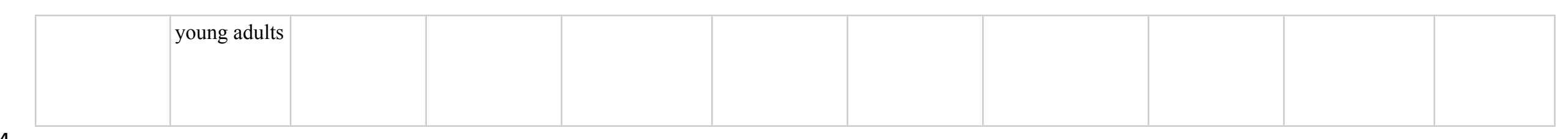




\section{PeerJ}

38

39 ITT: Intention to Treat Analysis 
Table 2 (on next page)

Weight loss for starters and completers 
1 Table 2: Weight loss for starters and completers

\begin{tabular}{|l|l|l|}
\hline Weight loss & Starters $(\mathbf{n}=\mathbf{7 5})$ & Completers (n=33) \\
\hline Weight loss (kg) & -2.38 & -3.81 \\
\hline Mean & 2.55 & 2.55 \\
\hline SD & -2.0 & -3.5 \\
\hline Median & $-12-+2$ & $-12-+1$ \\
\hline Range & $25=-4.0$ & $25=-4.6$ \\
\hline Percentile & $50=-2.0$ & $50=-3.5$ \\
& $75=-0.6$ & $75=-2.27$ \\
\hline \% Weight loss & -2.87 & -4.65 \\
\hline Mean & 3.06 & 2.74 \\
\hline SD & -2.2 & -5.0 \\
\hline Median & $-14.29-\_2.15$ & $-12.37-+1.38$ \\
\hline Range & $25=-4.94$ & $25=-5.47$ \\
\hline Percentile & $50=-2.2$ & $50=-5.0$ \\
& $75=0.72$ & $75=-3.1$ \\
\hline
\end{tabular}

